Full length article

\title{
Governance and networks for health co-benefits of climate change mitigation: Lessons from two Indian cities
}

\author{
Jose A. Puppim de Oliveira a,b,c,d,*, Christopher N.H. Doll ${ }^{\text {e }}$ \\ a Fundação Getulio Vargas (FGV), São Paulo School of Business Administration (FGV/EAESP) and Brazilian School of Public and Business Administration (FGV/EBAPE), Brazil \\ b Instituto COPPEAD de Administração, Universidade Federal do Rio de Janeiro, Brazil \\ c School of International Relations and Public Affairs (SIRPA), Fudan University, China \\ d United Nations University International Institute for Global Health (UNU-IIGH), Kuala Lumpur, Malaysia \\ e United Nations University Institute for the Advanced Study of Sustainability (UNU-IAS), Tokyo, Japan
}

\section{A R T I C L E I N F O}

\section{Article history:}

Received 17 December 2015

Received in revised form 24 June 2016

Accepted 23 August 2016

Available online 22 September 2016

\section{Keywords:}

Urban health

Co-benefits

Governance

Resilience

Networks

India

Transport

Waste

\begin{abstract}
A B S T R A C T
Health has been the main driver for many urban environmental interventions, particularly in cases of significant health problems linked to poor urban environmental conditions. This paper examines empirically the links between climate change mitigation and health in urban areas, when health is the main driver for improvements. The paper aims to understand how systems of urban governance can enable or prevent the creation of health outcomes via continuous improvements in the environmental conditions in a city. The research draws on cases from two Indian cities where initiatives were undertaken in different sectors: Surat (waste) and Delhi (transportation). Using the literature on network effectiveness as an analytical framework, the paper compares the cases to identify the possible ways to strengthen the governance and policy making process in the urban system so that each intervention can intentionally realize multiple impacts for both local health and climate change mitigation in the long term as well as factors that may pose a threat to long-term progress and revert back to the previous situation after initial achievements.
\end{abstract}

(c) 2016 Elsevier Ltd. All rights reserved.

\section{Introduction: system linkages between climate change and health in cities}

The challenges for achieving healthy societies pass necessarily through how cities are designed, governed and managed, as they concentrate an increasing part of the world's population. Cities are also key to determine the health of our planet as they are responsible for a large and growing part of the consumption of natural resources and emissions of greenhouse gases. The importance of cities to determine the future development patterns was recognized by the proposal of a specific Sustainable Development Goal: "Goal 11 - make cities and human settlements inclusive, safe, resilient and sustainable". ${ }^{1}$ Therefore, there is a need to understand the system linkages among

\footnotetext{
* Corresponding author at: Fundação Getulio Vargas (FGV), São Paulo School of Business Administration (FGV/EAESP) and Brazilian School of Public and Business Administration (FGV/EBAPE), Brazil

E-mail address: japo3@yahoo.com (J.A. Puppim de Oliveira).

1 Report of the Open Working Group of the General Assembly on Sustainable Development Goals. Issued as UN document A/68/970, available at http://undocs.org/A/ $68 / 970$.
}

urbanization, climate change, health outcomes and how governance 2 can strengthen those links.

System thinking in the urban context can provide a framework to analyze the connections among those different issues that contribute to health outcomes (ICSU, 2011; Bai et al., 2012). With the rise of climate change, a broader perspective on health beyond the traditional scientific fields are necessary to provide the right solutions beyond health systems (Proust et al., 2012; Puppim de Oliveira et al., 2015). In order to be more effective in improving health outcomes in cities, we need to move our discussions to include 'urban systems that affect health'. Systems' thinking on urban health allows us to map causal relations, unexpected consequences and drivers of the problems beyond the health systems and characteristics that can improve the health of urban residents.

\footnotetext{
${ }^{2}$ Governance here is defined as the "Governance refers to the institutions and processes through which societies manage the course of affairs at various scales" (Puppim de Oliveira et al., 2015). Several governmental and non-governmental actors help to shape governance in a certain context (sector and locality). Although governments have the legitimacy to create formal institutions that can change governance, informal institutions in society can shape governance as well.
} 
Development in general occurs through a series of transitions (urban, demographic, technological, epidemiological, energy) which interact with each other in complex, delayed and context specific ways. As such, the way in which urbanization is managed can have a radical outcome for urban health and well-being (McGranahan, 2007). Moreover, many cities in developing countries are particularly stressed by time and space compressed development (Marcotullio et al., 2005). In such an environment, urban management systems, which themselves are still developing their capacity, can become overwhelmed with the mass of rapid development facing them. Hence, the effectiveness of governance networks are of critical importance in addressing the health impacts of various urban systems.

The co-benefits approach is a concept that has emerged as a way to systematically realize multiple benefits of climate mitigation policy and mainstream them in conventional urban development. This concept is particularly relevant for Asia where issues like air pollution have been of primary focus (MOEJ, 2014) but may include environmental, health and other benefits of climate friendly policies, especially in the urban context (Puppim et al., 2013). The potential of the co-benefits approach to address issues of climate mitigation as well as local development concerns such as air pollution and health has been recognized by the Intergovernmental Panel on Climate Change Fifth Assessment Report (Seto et al., 2014).

Cities are also centers of knowledge and innovation (both technological and institutional) that can adjust the urban system towards better governance of health and the climate within cities. They are hubs of social and political movements that catalyze societal transformations. However, there is a need to reinforce institutional mechanisms that facilitate the dynamic exchange of knowledge and resources to generate and diffuse the innovative solutions we need for co-benefits. In this sense, collaborative approaches between global, national and local institutions are important to create the local and global institutions to generate health co-benefits in urban areas.

This paper examines the links between environmental and climate change mitigation policies and health by looking at the factors which operate in governance networks that allow for (or confound) continuous improvements to the urban system. The paper aims to understand the opportunities and barriers of creating health and climate co-benefits in urban systems through empirical data collected from the two case studies where health was the main driver for urban sectoral intervention. Remedying the deleterious effects of environmental pollution in an inherently complex environment requires a coordinated effort through networks of stakeholders, which invariably cuts across sectors, jurisdictions and management departments. Hence, coordinating urban policies require a series of top-down and bottom up approaches (Doll et al., 2013). With the network approach in mind, we analyze two cases of city-scale policy interventions in Indian cities aimed at improving health and environment in the city. The first is the improvements in waste management in Surat (India) after an outbreak of pneumonic plague in 1994. These changes had huge impacts on health and climate change mitigation, besides reducing waste (Kapshe et al., 2013). The second case is the improvements in air quality in the transportation sector driven by a court decision to improve air quality in the city of Delhi. Similar to the Surat waste case, the Delhi transportation case had health as one of the main drivers to urban interventions coming from the court decision. However, in contrast to the Surat case, air quality in Delhi initially improved but after a few years got even worse than before. The cases are contrasting in a number of ways beyond the different sector they address. In particular they describe the responses to two different types of problems, one the response to a deadly outbreak of the plague (a discontinuous shock the system), the other, persistently worsening air pollution caused by a range of economic activities (a slow onset event). These two types of problems are also characteristic of either side of the epidemiological transition where a society switches from a predominance of infectious (e.g. plague) to non-infectious diseases such as asthma, heart disease and obesity (McGranahan, 2007).
The comparison between the two networks in each case helps to identify the possible ways to strengthen the governance and policy making process in the urban system so that each urban intervention can intentionally have continuous improvements and realize multiple impacts for both local health and climate change mitigation, and not revert back to a previous stage after initial steps are taken. There is also a need to develop the governance mechanisms that help to build the cities' capacities to continuously integrate health in urban development processes which create synergies between health and climate change. Thus, the paper compares the two cases to discuss how to assess local capabilities to integrate health in their respective urban governance. We conclude with a discussion on the institutions required at different levels to steer the integration of the health related development goals towards a more sustainable urban path that can address these twin global-local challenges.

\section{System resilience and building networks in the public sector}

We take an agnostic view of the term resilience, defined as the ability of a system to return to its initial state. In many cases resilience can be a pernicious factor leading to outcomes which are detrimental to the environment as well as human health and needs to be subverted in order to produce desired outcomes. Many urban systems are resilient to health outcomes in undesirable ways. Poverty, discrimination and their detrimental outcomes have persisted for centuries and are reinforced by systemic reproductions of behavior and policies which encode this resilience into everyday life. Understanding how governance structures contribute to such reproductions is a key component to weaken the resilience of systems, which produce unhealthy outcomes. A strong network of organizations is needed to break the resilience of such systems. A single organization is unlikely to have the capacity to make major changes, as the system depends on diverse actors in the public sector and beyond.

Networks in the public sector have been key to advance different public policies (Marin, B. \& Maynts, R., 1991; Powell, W.W., 1990; Pierre and Peters, 2000; Provan and Lemaire, 2012). However, there are limited empirical studies on network outcomes (Turrini et al., 2010). Thus, we analyze how organizational networks in the public sector can be built and maintained to break the resilience of deleterious urban systems by making continuous urban improvements that lead to better health conditions in cities, and not just have sporadic but unsustainable improvements as we see in many cases. Policy support to climate mitigation, which is rising in many cities around the world, can be an important component to build strong urban health networks because of the strong climate co-benefits. Systems thinking in urban health can help to identify the co-benefits between health outcomes and climate friendly urban systems (Puppim de Oliveira et al., 2015), identifying the main points in the public sector networks that can improve governance for urban health.

The literature identifies five features to determine the effectiveness of organizational networks in the public sector: involvement of multiple levels; network design; appropriate governance; building and maintaining legitimacy; and stability (Provan and Lemaire, 2012). We briefly examine each of these in turn. The first feature: involvement of multiple levels, refers to the importance of "multiplexity" of the relationship among the different partners in the network, i.e. the network should have a multiplicity of relationships among its members and not rely on one single person in each organization or one single organization for the connections among actors. Networks relying on one actor may be weakened when this actor leave the organization or the network.

The second key feature for effectiveness is network design. While fragile links and coordination among members can create weak networks, highly integrated networks may not lead to effectiveness, as transaction costs may be high and commitment to the network among actors may decline as demands on participants begin to overburden resources. A mix of relationships with different degrees of intensities among different actors should be built into the network. Strong ties 
among certain actors may be needed for certain tasks, and weaker ties may be enough for other tasks and other actors.

Appropriate governance is another essential feature of an effective network and is linked to its design. Even though there is limited research on the best form of governance in multi-organizational networks (Provan and Lemaire, 2012), a few factors have been identified as important for effectiveness. Firstly, trust among organizations and individuals in the network is fundamental to governance. Without trust, a network cannot work properly. Secondly, the facilitator organization or individual can determine the good governance of a network. While shared participative network may work for small networks of five or six organizations, large networks generally require a lead organization of an administrative hub.

The fourth important feature for effective networks is its legitimacy, both internal (among network members) and external, and again trust is an important component to build legitimacy. While internal legitimacy is crucial for the functioning of the network, particularly in its beginning, external legitimacy can help to extend the membership of the network for more complex tasks and bringing outside resources to achieve the network goals.

Network stability is the fifth feature to determine effectiveness. Keeping the network stable in different situations as it evolves is important to deliver effectively. While certain degree of flexibility in the relations among actors may help in performing certain tasks, such as disaster management (Kapucu and Van Wart, 2006). A high degree of flexibility can lead to unstable networks that have difficulty to perform any or certain tasks effectively. Thus, effective networks need to be stable at their core, such as the tasks of the key organizations but can be flexible in the relations with peripheral organizations.

\section{Cases in India}

The research was based on the case study method (Ragin and Becker, 1992) to examine how health has been a catalyst to urban transformation and identifying the conditions that make the changes resilient to returning to the existence of the previous problems. It draws on cases in two Indian cities in two sectors: waste (Surat) and transportation (Delhi). Both cases had health as one of the main drivers of urban change and lead to improvements in waste management in Surat and transportation and had huge impacts on health and climate change mitigation.

The case study method is recommended to identify complex issues where research and data are abundant but the explanation about the different phenomena cannot be made with pure quantitative analysis. Field visits to India was carried out by the authors between 2011 and 2015, when they had the opportunity to conduct semi-structure interviews with people in government, civil society organizations, NGOs and experts from the universities working in the area. We also analyzed several documents related to the area and event, such as scientific and consulting reports, academic papers and news from newspapers and reliable webpages.

\subsection{The case of waste Surat}

Surat is located near to the coast in the Gujarat State in Western India, a city near the coast, and it is bisected by the Tapi River (Fig. 1). It is an industrial city with industries such as textile, chemical, petrochemical and jewelry. The city is one of the world's hubs for diamond cutting. The population was over 4.47 million in 2011 (SMC, 2016),

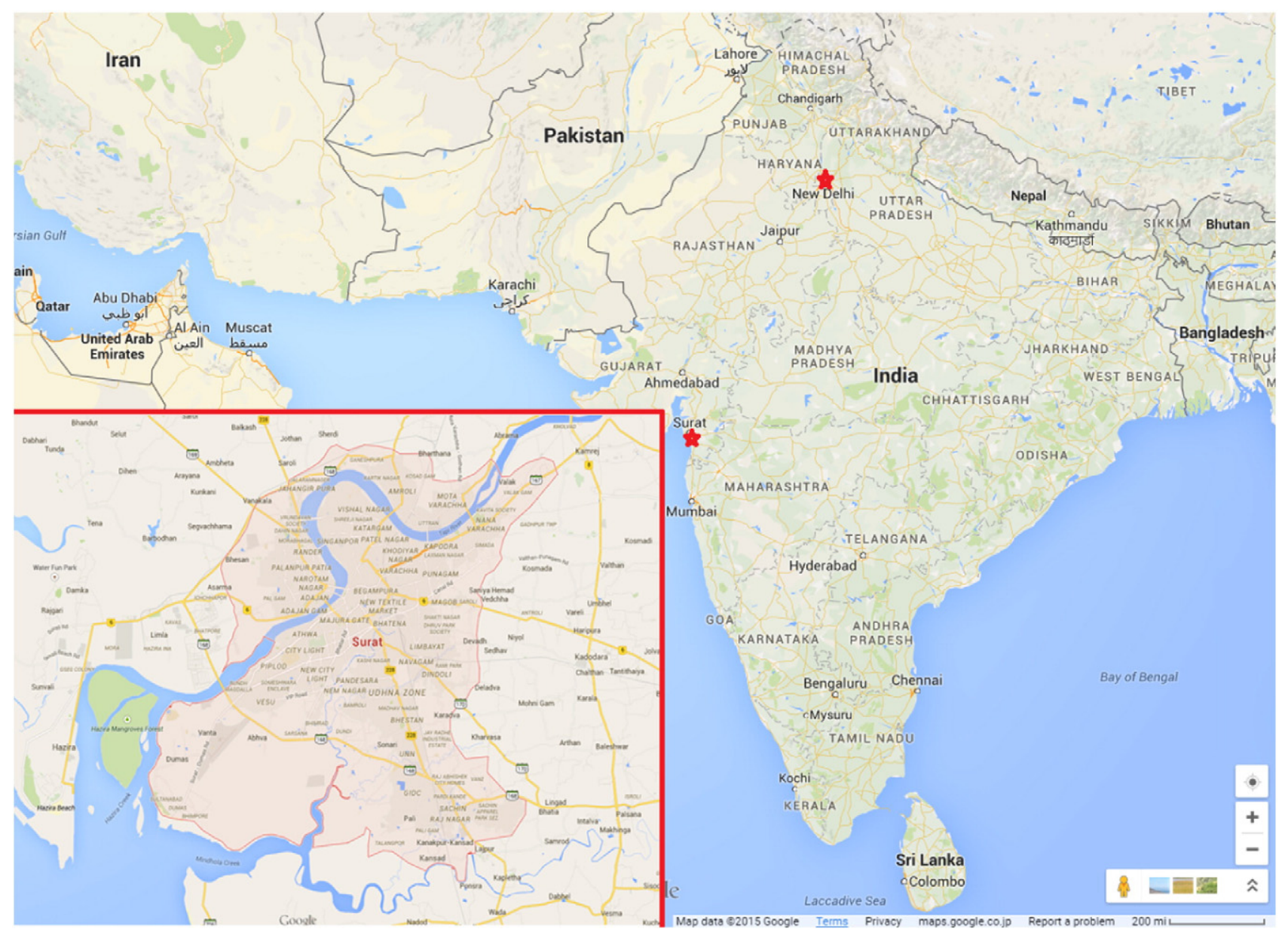

Fig. 1. Location of Delhi and Surat in India with inset map of Surat. 

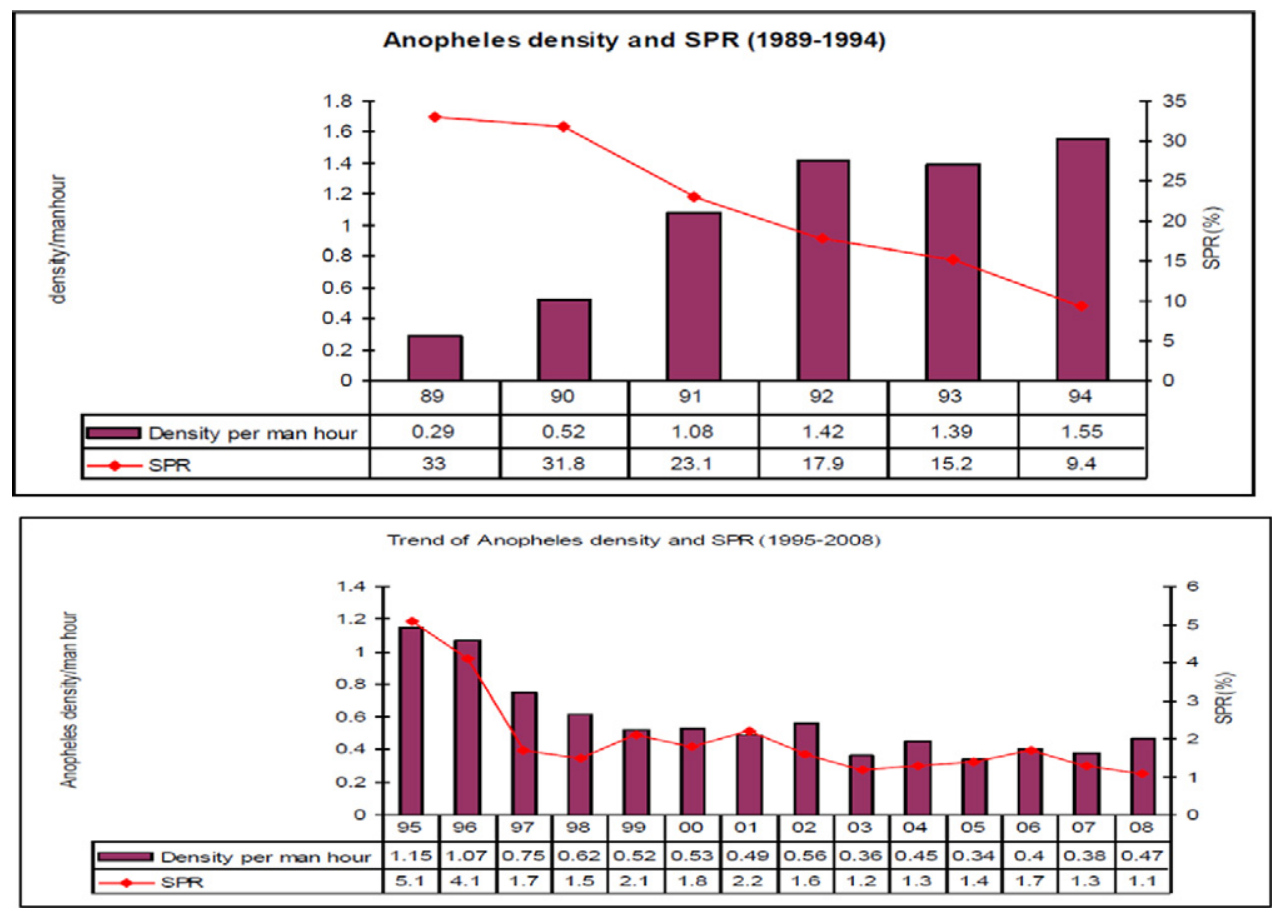

Source: Surat Health Sector Study, India, 2011

Fig. 2. Reduction of Anopheles mosquito and Slide Positive Rate (SPR, a proxy for malaria incidence) in Surat before and after 1994. Source: Surat Health Sector Study, India, 2011.

one of the fastest growing cities in India. The Surat Municipal Corporation (SMC) is the local administrative entity for the city of Surat, having its responsibilities determined by the State of Gujarat. ${ }^{3}$

Prior to 1994, the city was affected by regular floods and lack of proper drainage and sanitation systems. The first drainage system was introduced in 1956 for a population of up to 300,000 inhabitants. However, the system was serving only $13 \%$ of the area and $33 \%$ of the population in 1991. Sixty percent of the slums had no drainage. Besides drainage and sewer system, the SMC also had limitations in regularly collecting garbage and cleaning the streets.

The city was affected by a large flood from the Tapi River followed by an outbreak of pneumonic plague in September of 1994. The exact number of persons contaminated and deaths is unknown. The New Civil Hospital (NCH) documented at least 1013 patients with symptoms or suspicion of contamination between September and November 1994, and at least 48 deaths were recorded (Shah, 1997, pp. 36-37). However, the impacts were widespread as many people left the city with fear of contamination or quarantine and there was a risk of spreading the diseases to other parts of India and internationally, triggering an alert from the World Health Organization.

City and state level government reacted through several actions and initiatives. Initially, tremendous efforts were made by the SMC and state government agencies with the support of the national government to control the spread of the plague and treat the patients, such as trying identifying the plague cases, giving proper treatment and put patients in quarantine (Shah, 1997). The city also went through a thorough cleanup process to remove all garbage and potential plague vectors and their habitats.

\footnotetext{
${ }^{3}$ In India, the mayor (elected official) heads the corporation having a commissioner (a public servant) in charge of the executive administration. In Surat, The General Board composed of 116 elected councillors (four of each of the 29 wards) is the governing body of Surat Municipal Corporation (SMC, 2016). SMC has several departments for its various responsibilities, such as engineering, health (including solid waste management), revenue and social services. In each of the seven zones of the city, there is a zonal chief and a deputy in charge of health (covering solid waste management) (SMC, 2016).
}

Later on the city went through a huge managerial change to deal with waste and health, particularly increasing the accountability of the governmental agencies in providing a clean environment. The SMC therefore developed the capacity to build an exemplary solid and sewage management systems in the Indian context. Moreover, the city has continuously incorporated many innovative technologies in the area such as being the pioneer in installing captive power plants in their sewage treatment. As a result Surat has become one of the cleanest cities in India with several co-benefits such as the generation of an average of 1.5 to 2.5 million kWh of electricity every year as well as significant mitigation of climate change (Kapshe et al., 2013). The city also had co-benefits in health such as reduction in malaria cases and mosquitoes (Fig. 2).

There were several organizational and managerial changes in the cities after 1994 to increase management effectiveness and accountability. Instead of the SMC departmental compartmentalization for dealing with the whole city, supervisory authority with financial and administrative powers was decentralized to seven zonal chiefs with responsibility for all functions within their zones. The Chief Engineers of SMC's main departments were appointed as zonal commissioners to motivate them. The new organizational structure also expanded the powers of the health official to also take charge of waste management in each zone (see Fig. 3). Furthermore, the commissioner and senior officers were required to spend time in the field, generally in the mornings, instead of focusing solely on office work. As a result, there were significant improvements in sewage, solid waste management and flood control, with initiatives of new solid waste management collection systems with new technologies (one of the best in India), drainage of standing water, improvements in the sewer systems and awareness raising programs in the population regarding links between waste, sewage and health.

\subsection{The case of transport Delhi}

Delhi has been the capital of India for over a century. Its status and attraction as a capital city has also resulted in rapid urbanization, particularly since independence in 1947 with the population growing more than 10-fold in the intervening period (see Ahmad et al. (2013) for a 


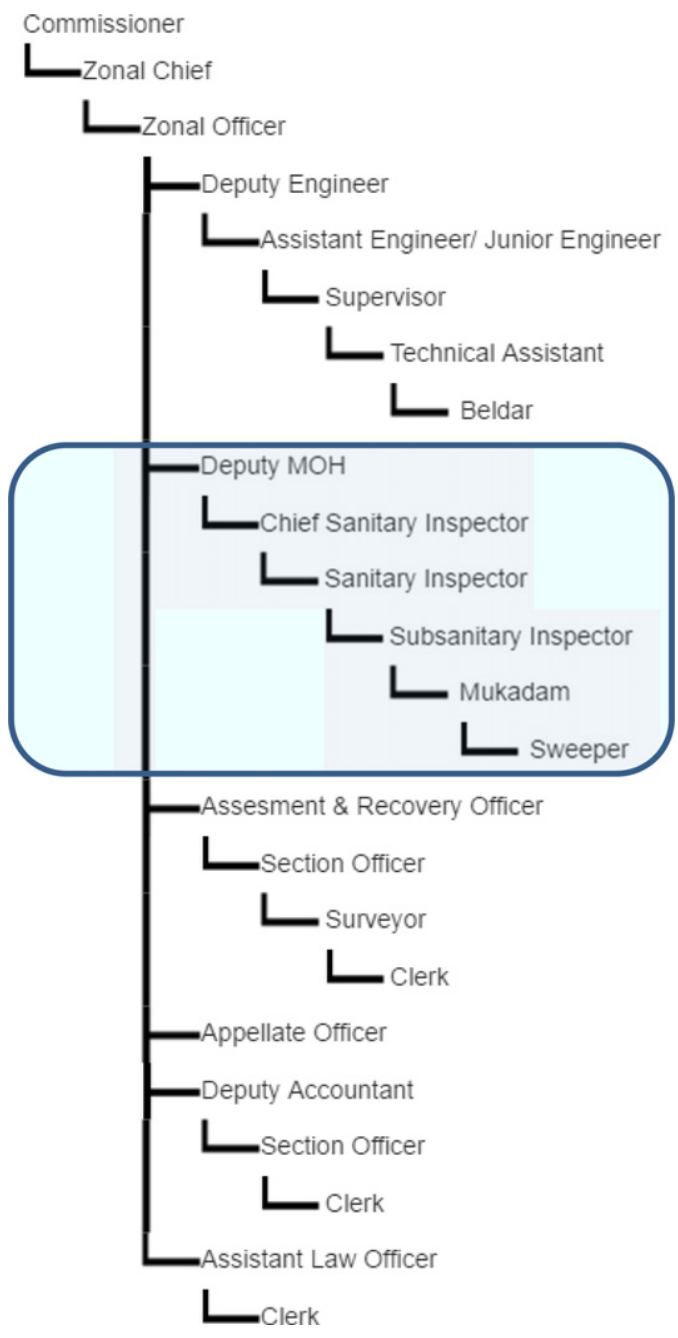

\section{Zone's Health Department}

Fig. 3. Organizational structure of a zone in the Surat Municipal Corporation (SMC, 2016).

comprehensive profile of the city). Associated with the growth of an ambitious city that is the seat of government of the second most populous country in the world is a growth in motorization that greatly exceeds other cities in India. According to data in Singh (2012), the number of private cars in Delhi more than doubled from 870,000 to 1.8 million between 2000 and 2009, dwarfing levels of even the other India megacities of Mumbai and Kolkata (510,000 and 314,000 respectively in 2009). Delhi already has a level of car ownership that exceeds more developed countries and is currently higher than the nationally projected figure to 2030 (Portugal-Pereira et al., 2013). In addition to cars, there are many buses, motorcycles and auto-rickshaws plying the streets, which all contribute to the poor air quality in the city. Although not the only source of air pollution, transport emissions accounted for over $60 \%$ of certain kinds of air pollution in the city by the mid-1990s (Sharma and Roychowdhury, 1996; GoI, 1997). Against this backdrop are wider city concerns of urban transport management, relieving congestion and public transport provision, which all come into play when considering transport solutions for any city.

The case of Delhi focuses on the role of an active judiciary, which has been instrumental in guiding many of the environmental actions in the city. Dreyfus (2013) describes how India's common law judicial system allows various parties to bring public interest litigation (PIL) on behalf of powerless parties for the public good. Moreover, the judiciary itself can issue its own rulings based on publicly available information. This system started in the 1980s when the environmental lawyer MC Mehta petitioned the court to direct the both national and Delhi government to tackle pollution (Narain and Krupnick, 2007). Since then, a raft of decisions have been passed in the areas of land management (including industrial relocation), water and air pollution (Dreyfus, 2013).

The publication of reports such as 'Slow Murder: The deadly story of vehicular pollution in India' (Sharma and Roychowdhury, 1996) and concerns over the rate of premature deaths due to air pollution maintained a focus that resulted in hundreds of often very technically specific decisions taken by the court. These included fuel exhaust standards in 1991 and the phasing out of leaded fuel (1995-1998), vehicle inspection programs and the limiting of the age of vehicles allowed on the road (1997). Arguably the single most important decision, and of particular interest to this case, was a 1998 ruling that mandated the use of compressed natural gas (CNG) in all government buses, taxis as well as autorickshaws (3-wheelers) by 2001 (see Goel and Guttikunda, 2015 for a full list of policies and measures undertaken in Delhi).

The ruling was transformative in reducing mobile sources of air pollution in the city. Despite the fact that the mandate only applied to a limited type of vehicles, reductions of over $30 \%$ for $\mathrm{SO}_{2}$ and smaller reductions of $3-7 \%$ for particulate matter (PM) with a $14 \%$ increase in $\mathrm{NO}_{\mathrm{x}}$ was observed between 2000 and 2003 (Chelani and Devotta, 2007). Improvements in excess levels of all kinds of health risks were also noted around this time though they then began to increase continuously after 2002 (Nagpure et al., 2014). Evaluation over a longer period, shows that PM levels in fact declined around 15\% from 2002 to 2007 but then increased massively 75\% in the following 5-year period to 2012 (EPCA, 2014). 
While the case of Delhi's judiciary can be claimed to be a positive case of widened interaction enhanced citizen action on environmental issues (Puppim de Oliveira et al., 2015) especially against a business as usual baseline of total inaction, it can also be shown that while necessary it is not a sufficient condition to create a sustained change. It is also necessary to examine the broader context of the aggressive increase in motorization mentioned at the top of this section. In particular, a number of pricing policies seem to be the undermining the position of clean fuels. Following the switch, CNG enjoyed a large price differential over diesel, the price of which remained stable and was around $40 \%$ cheaper 2002-2009. Since then the price of CNG has doubled and was just 7\% cheaper than diesel in 2013 (EPCA, 2014). The relatively cheap cost of diesel compared with petrol has seen diesel fuelled vehicles become an increasing presence in the private vehicle fleet (Narain and Krupnick, 2007; EPCA, 2014) and now accounts for over half of new car sales despite the higher upfront cost. Other factors noted by the Environment Pollution (Prevention and Control) Authority for the National Capital Region (NCR) (EPCA, 2014) include:

- Rapid motorization based on poor quality fuels and vehicle technology (especially for trucks and buses)

- Patchy coverage of emission standards both nationally and within the NCR

- Public transport capacity not keeping up with increasing demand

- Hidden driving subsidies (parking and taxation)

- Limited support for walking and cycling

Thus, the issue of sustainable mobility goes further than just switching to cleaner fuels and for congestion in particular, efforts largely hinge on shifting private car users into public modes. To this end, an extensive metro system is in the third of four phases of construction and has been shown to provide modest reductions in air pollutant emissions with greater potentials based on increased ridership and mode shifts to the metro (Doll and Balaban, 2013). Plans for a Bus Rapid Transit (BRT) were also formulated but this has suffered a much more troubled implementation with only a $5.8 \mathrm{~km}$ pilot BRT project in South Delhi so far attempted. Yet even this fell under the glare of the courts, when another PIL was enacted by disgruntled car users owing to the increased congestion of that corridor (BBC, 2012). A widely criticized report (Roychowdhury, 2012; EPW, 2012) from the Central Road Research Institute was used as the basis for the subsequent ruling that cars could use the dedicated bus lanes to ease congestion, thus denying the BRT its defining feature!

Despite the initial success of the orders, air pollution and associated health problems remain a significant and increasing problem. The problem is so bad that it was recently proclaimed to be the world's most polluted city based on a WHO study of $\mathrm{PM}_{10 / 2.5}$ levels over 1600 cities (WHO, 2014). This gained worldwide coverage with some suggestions that the US President's 3-day visit to the capital would take $6 \mathrm{~h}$ of his life expectancy (Bloomberg, 2015).

The Delhi case was not ultimately sustainable because the ruling was partial to the entire fleet of vehicles and focused mainly on quick-win solutions rather than more structural issues. As such there needed to be counter measures to restrict the use of private vehicles in preference to public transport. As there was very little appetite for this, it addressed the problem of vehicular air pollution in a piecemeal way, which, while an observable impact could be initially detected, further measures were required to substantiate the initial gains but were subsequently lost as broader energy and economic policies won out.

\section{Building capabilities and networks in local governments: collabo- rative approaches between global, national and local institutions}

In order to analyze the two cases, we use the five features identified in the literature to determine the effectiveness of organizational networks in the public sector described in Section 2, namely: the involvement of multiple levels; network design; appropriate governance; and legitimacy and stability. Table 1 summarizes how the five features manifested themselves in each case.

Effectiveness depends on the network's capacity to achieve continuous improvement in the health conditions of the city by bringing in resources and improving the organizational capacity of the network and the different actors involved.

Regarding the involvement of multiple levels, the network in Delhi was heavily centralized in the judges and their decisions while in Surat the decentralization in the SMC helped to build the network around multiple local individuals (zonal chiefs). The dependence on one organization reduced the effectiveness of the network in Delhi, as the courts did not have the capacity to expand the network for enforcement by its own. Once their decisions were made, their role in supporting the implementation was very limited. Thus, overtime the system started to have the same pollution problems as before.

In the case of Surat, the SMC had more control over the design of the network, and the decentralization helped the zonal chiefs to determine the degree of intensity of the relations in their own local networks. In Delhi, the relations among actors were intense and determined by the court rulings, with little room for balancing the relations, creating an overembeddedness for the actors (Uzzi, 1997) in the beginning of the implementation phase, but having the intensity of engagement waning down over time and the court had no influence in improving the design after the decisions.

There was no proper governance mechanisms in the case of Delhi. A large network was used for the enforcement of the rulings, but there was no intensive participation or management of the organization. In Surat, while decentralized governance allowed local nodes (zones) to balance the intensity of the relationships with local actors as needed, the commissioner still played a central role in the general management of the network by informational flow, monitoring and providing resources to local nodes as needed.

Legitimacy was problematic in Delhi. While the enforcement was delegated to different organizations, it was a mix of civil society groups, judges and the city pushing for the PILs, creating a lack of internal trust among them. Moreover, external trust between enforcement network and regulated actors were low creating a legitimacy gap. This hindered acceptance of the authority of the government actors what made difficult enforcement and collaboration with regulated actors. The interests of government and polluters were driven farther apart preventing further advancements in the environmental standards. In Surat, the alignment of the interest among the different actors to clean up the city and curb further cases of the plague helped to build trust and reinforce the government legitimacy in the network. The clean-up depended on the capacity of the city for waste management, which in turn depended on the citizens to collaborate in waste management. On the other hand, the citizens were the first to gain with the benefits of public health, and the city management and employees increased their morale by changing the bad reputation Surat had as the dirtiest city in India.

Finally, the stability of the Surat network grew with the decentralization as the network evolved contrasting with the lack of stability in the Delhi case. In case of the latter, stability depended on the court rulings, which were somewhat ad-hoc in nature as they were not solely motivated to tackle air pollution. They did not allow much flexibility to change and adapt as the network evolved. As the implementation of the enforcement moved to the city government, the courts played a less essential role and the network was weakened and unstable. Moreover, the ongoing efforts and proximal actions by the SMC contrasts with the one-time and distant nature of court rulings, which undermined stability in the long run as the network became more dispersed over time.

Thus, in the case of Delhi, the flagship legal ruling to CNG shift was one positive measure in a raft of otherwise conflicting policies. The existence of a national low taxation policy on diesel making it an attractive choice for car users was ultimately counterproductive, while other 
Table 1

Key features for network effectiveness in Surat and Delhi cases.

\begin{tabular}{|c|c|c|c|}
\hline Key features & Surat & Delhi & Analysis of the difference \\
\hline $\begin{array}{l}\text { Involvement of multiple } \\
\text { levels }\end{array}$ & $\begin{array}{l}\text { - Plague led to decentralizing its decisions } \\
\text { and operations to zonal chiefs } \\
\text { - Decentralization led to the creation of a } \\
\text { multiplicity of relations with various } \\
\text { nodes }\end{array}$ & $\begin{array}{l}\text { - The courts became the focus of the net- } \\
\text { work for pushing for the clean-up of the } \\
\text { air in Delhi. } \\
\text { - Network function essentially depended } \\
\text { on the court } \\
\text { - Relations with the other actors were } \\
\text { largely the same through court rulings. }\end{array}$ & $\begin{array}{l}\text { A more centralized network led by court } \\
\text { through the rulings pushed by the PIL led to } \\
\text { difficulties to deal with the multiplicity of } \\
\text { regulated actors. }\end{array}$ \\
\hline Network design & $\begin{array}{l}\text { - The new design of the SMC dispersed the } \\
\text { burden of coordinating the relations } \\
\text { among the zonal chiefs } \\
\text { - Chiefs could balance the intensity of the } \\
\text { relations with the local actors, creating } \\
\text { more intense relationships when needed }\end{array}$ & $\begin{array}{l}\text { - The courts occupy a privileged position in } \\
\text { the network hierarchy } \\
\text { - Ability to force cities to enforce laws on } \\
\text { private and public actors. } \\
\text { - No balance in the relationships (see Ap- } \\
\text { propriate governance) }\end{array}$ & $\begin{array}{l}\text { The capacity to manage the design of the } \\
\text { core of the network in the case of Surat } \\
\text { contrasts with the rigid design in Delhi. }\end{array}$ \\
\hline Appropriate governance & $\begin{array}{l}\text { - The decentralization allowed a reduction } \\
\text { in the number of organizations in each } \\
\text { network } \\
\text { - This led to a more participative gover- } \\
\text { nance and helped in the management of } \\
\text { the relations with local actors according } \\
\text { to the needs of the zone }\end{array}$ & $\begin{array}{l}\text { - A series of rulings created incremental } \\
\text { changes in ad-hoc areas of the transport } \\
\text { system. } \\
\text { - Other actors lacked the capacity to rein- } \\
\text { force these gains with complementary } \\
\text { policies to balance what was coming from } \\
\text { the court. } \\
\text { - Courts did not play the role of managers } \\
\text { (nor should they); thus, the network was } \\
\text { not participative or had a proper manager. }\end{array}$ & $\begin{array}{l}\text { There was no proper network governance in } \\
\text { the case of Delhi while Surat had the SMC as } \\
\text { manager with the decentralization helping } \\
\text { in govern a large number of actors. }\end{array}$ \\
\hline $\begin{array}{l}\text { Building and maintaining } \\
\text { legitimacy }\end{array}$ & $\begin{array}{l}\text { - Zonal chiefs brought the municipal gov- } \\
\text { ernment closer to the local actors and in- } \\
\text { creased the responsiveness of the SMC to } \\
\text { local needs } \\
\text { - Trust was improved between SMC and } \\
\text { local actors } \\
\text { - This helped to build legitimacy to SMC } \\
\text { and bring support to the health initiatives } \\
\text { of the city }\end{array}$ & $\begin{array}{l}\text { - High degree of mistrust among the differ- } \\
\text { ent actors in the network } \\
\text { - Although the court and city used their le- } \\
\text { gitimate 'police' power of state actors to } \\
\text { enforce the environmental legislation } \\
\text { - Lack of legitimacy for the network to per- } \\
\text { form other tasks that needed a more vol- } \\
\text { untary approach }\end{array}$ & $\begin{array}{l}\text { The city had to enforce the rulings, and the } \\
\text { own court decision undermined the } \\
\text { legitimacy of the city. There was also a lack } \\
\text { of trust between the actors behind the PIL } \\
\text { and court on the one side, and the city and } \\
\text { regulated actors in the other side. }\end{array}$ \\
\hline Stability & $\begin{array}{l}\text { The decentralization helped SMC to be flexible } \\
\text { in its relations at the local level } \\
\text { - Each zonal chief could manage the local } \\
\text { waste supporting network according to its } \\
\text { capacity and local needs } \\
\text { - SMC kept the core of the city-wide net- } \\
\text { work formed by the chiefs stable to per- } \\
\text { form the core activities, including } \\
\text { network management. }\end{array}$ & $\begin{array}{l}\text { - Court decisions did not lead to the forma- } \\
\text { tion of a stable network. } \\
\text { - Enforcement network was formed by the } \\
\text { courts with pressure from civil society ac- } \\
\text { tors in order to have the city enforce leg- } \\
\text { islation over regulated actors. }\end{array}$ & $\begin{array}{l}\text { The network formed in Delhi had a weak } \\
\text { core, formed basically by the court. As soon } \\
\text { as the effects of the ruling ceased, network } \\
\text { was weakened. }\end{array}$ \\
\hline
\end{tabular}

measures to tackle private car use, most notably parking charges already some of the lowest in the world, are wildly unpopular and have also been challenged in court by a trade association (Roychowdhury, 2011); precisely the sort of middle-class groups that PIL sought to empower. The age-cap to the car fleet passed in 1997 mentioned in the case description was deferred by the government due to popular protests coinciding with elections that year and was implemented only later in 1998. Indeed, although the PIL system opens a space for wider participation, it has been noted that given the resources and capacity required to bring such cases, it runs the risk of becoming a tool for the elite that not only ignores the plight of the poor, but actively discriminates against them (Dreyfus, 2013).

Although transport is but one contributor to air pollution in the city, the case shows that even within a single sector, initiatives aimed at reducing air pollution have been crowded out by more resilient attitudes and policies, which have reproduced activities that not only increase global carbon emissions but also air pollution and subsequent health effects.

The irony is that PIL is being used to both advance normative environmental goals (such as clean air) as well as block measures that may aid this objective because they affect the reproduction of other activities of stakeholders. Ultimately, the network in Delhi was ineffective in mediating the aims of the different actors in the transport system in order to produce improved environmental and health outcomes. Moreover, the nature of the State actors involved also affected the effectiveness of the public network. The courts themselves, only pass decisions and do not manage the process of those decisions; unlike city governments, such as SMC, that have are continuously involved in decisions. Other entities charged with managing the city's transport needed to ensure that a coherent approach was adopted, which did not happen effectively over time.

Other factors may also affect the difference in networks, governance structure and urban management in the two cases. Firstly, the size of the metropolitan areas are very different, Delhi being much larger than Surat. Secondly, Delhi has a famously fragmented system of urban governance with a mix of national and local governments involved in management (Ahmad et al., 2013), complicated by a set of local governments that are part of the metropolitan area (or the urban system) but managed by surrounding states. In fact, it is precisely this overlapping and at times competing structure that created governance deficit and consequently, a space for the court decisions to act more decisively (Dreyfus, 2013). However, improvements in governance can be credited in large part by the changes in the structure of the SMC, as the changes in many indicators can show (such as Fig. 2). The plague drove external forces to break the resilience of the system to allow the changes. Decentralization was key to improve accountability and the capacity of the public network to respond more effectively in the provision of urban services.

\section{Conclusions and recommendations}

Building effective networks are fundamental to tackle environmental pollution and improve health conditions in cities. In many instances, the networks need to evolve to make continuous improvements and 
break the system resilience that often tend to hold back the health and environmental conditions to previous states. The two cases in this paper provide examples of network building that achieved different results. While the Surat case witnessed a remarkable change in waste management and health over time, the case of Delhi described a situation where the conditions initially improved through the court rulings on the enforcement of environmental standards on individuals or organizations but worsened due to the absence of control in the growth of the number of polluters.

Using the five features to understand effectiveness of networks helped us to analyze the cases and pinpoint the differences between the evolutions of the two networks. The key fact in the Surat network was the decentralization of SMC that built a design that helped to improve governance and legitimacy among the different actors. Decentralization also made the network stable to continuously bringing new actors and resources to increase the waste collection capacity, including mastering new technologies.

There are some important lessons and recommendations relevant to break the resilience of malfunctioning urban systems. The first is the involvement of a multiplicity of actors that can keep the changes in the system overtime and not relying on one single organization, such as in the case of the Supreme Court in Delhi. Secondly, the design of the network should allow different relations among actors to avoid high transaction costs or weak linkages. A decentralized system like in Surat may work well, but it needs some coordination at higher level to make sure the local "sub-network" is effective and well-coordinated. Thirdly, an appropriate governance requires high degree of trust among the members of the network that can be built only overtime after many interactions among them, as well as a leading coordinating organization for daily activities, such as in the case of the SMC and its zonal modes in Surat. Fourthly, the network needs to build its legitimacy as a social and political entity to be able to advance its aims in society and counter the organizations that want to keep the system or return it to the previous state, such as in the case of Delhi. Finally, an effective network to change urban system requires stability in the long term, particularly at its core, which did not happen in the case of Delhi.

The Surat case is, in a sense, somewhat simpler. It describes the construction of network to address a problem after the shock of a devastating disease outbreak. In such a situation, there was less resistance to create a parallel process with the consent of the existing governance network. The case of Delhi has less to do with the construction or design of the network rather than the effectiveness of it in response to a slow onset event of ever increasing air pollution. Despite well-intentioned interventions from the courts of a period of years, the sense of urgency was lacking. Beyond the court decisions, the changes needed to bring wider systemic change to the transport system started to conflict with the norms and interests of the more powerful and influential actors in the system. Even though restricting private vehicle use had wider co-benefits of easing congestion and therefore shorter journey times, they faced stronger opposition, so inevitably the local authority passed policies of least resistance.

These two cases show the importance of understanding the system and motivations of actors within. By mapping out the various actors and their relationships, it may be possible to identify where such conflicts in the network arise and while neat solutions are rare if not impossible, should identify entry points where progress needs to be made in order to address the issues which can thwart sustainable change earlier in the process.

\section{Acknowledgments}

The authors acknowledge the contribution of the anonymous reviewers for their suggestions during the review process. They also thank the support of the United Nations University Institute of Advanced Studies (UNU IAS) and the United Nations University International Institute for Global Health (UNU IIGH) as well as all the interviewees.

\section{References}

Ahmad, S., Balaban, O., Doll, C.N.H., Dreyfus, M., 2013. City profile: Delhi revisited. Cities (31), 641-653 http://dx.doi.org/10.1016/j.cities.2012.12.006.

Bai, X., Nath, I., Capon, A., Hasan, N., Jaron, D., 2012. Health and wellbeing in the changing urban environment: complex challenges, scientific responses, and the way forward. Curr. Opin. Environ. Sustain. 4 (4), 465-472

BBC, 2012. Delhi row over bus lane reveals class divide. (Available at:) http://www.bbc. com/news/world-asia-india-19572583.

Bloomberg, 2015. Mr. President, world's worst air is taking 6 hours off your life. (Available at:) http://www.bloomberg.com/news/articles/2015-01-26/mr-presidentworld-s-worst-air-is-taking-6-hours-off-your-life.

Chelani, A.B., Devotta, S., 2007. Air quality assessment in Delhi: before and after CNG as fuel. Environ. Monit. Assess. (125), 257-263.

Doll, C.N.H., Balaban, O., 2013. A methodology for evaluating environmental co-benefits in the transport sector: application to the Delhi Metro. J. Clean. Prod. (58), 61-73 http:// dx.doi.org/10.1016/j.jclepro.2013.07.006.

Doll, C.N.H., Dreyfus, M., Ahmad, S., Balaban, O., 2013. The institutional framework for urban development with co-benefits: the Indian experience. J. Clean. Prod. (58), 121-129 http://dx.doi.org/10.1016/j.jclepro.2013.07.029.

Dreyfus, M., 2013. The Judiciary's Role in Environmental Governance, the Case of Delhi. Environmental Policy and Law Vol 43, num 3 p. 167.

EPCA, 2014. Report on priority measures to reduce air-pollution and protect public health. Environment and Pollution (Prevention \& Control). Authority for the National Capital Region.

EPW, 2012. Against public interest. Economic and political weekly. (Vol - XLVII No. 33, August 18, 2012. Available at:) http://www.epw.in/editorials/against-publicinterest.html (accessed through:) http://urbanemissions.blogspot.jp/2012_08_01_ archive.html.

Goel, R., Guttikunda, S.K., 2015. Role of urban growth, technology, and judicial interventions on vehicle exhaust emissions in Delhi for 1991-2014 and 2014-2030 periods. Environ. Develop. 14, 6-21. http://dx.doi.org/10.1016/j.envdev.2015.03.002.

GoI, 1997. White Paper on Pollution in Delhi with an Action Plan. Ministry of Environment \& Forests, Government of India Available at: http://envfor.nic.in/divisions/cpoll/ delpolln.html.

ICSU, 2011. Report of the ICSU Planning Group on Health and Wellbeing in the Changing Urban Environment: A Systems Analysis Approach. International Council for Science, Paris, France.

Kapucu, N., Van Wart, M., 2006. The evolving role of the public sector in managing catastrophic disasters lessons learned. Adm. Soc. 38 (3), 279-308.

Kapshe, M., Kuriakose, P.N., Srivastava, G., Surjan, A., 2013. Analysing the co-benefits: case of municipal sewage management at Surat, India. J. Clean. Prod. 58, 51-60.

Macotullio, P.J., Williams, E., Marshall, J.D., 2005. Faster, sooner, and more simultaneously: how recent road and air transportation $\mathrm{CO}_{2}$ emission trends in developing countries differ from historic trends in the United States. J. Environ. Develop. 14 (1), 125-148. http://dx.doi.org/10.1177/1070496504273716.

Policy networks. In: Marin, B., Maynts, R. (Eds.), Empirical Evidence and Theoretical Considerations. Frankfurt a. M.Campus Verlag

McGranahan, G., 2007. Urban Environments, Wealth and Health: Shifting Burdens and Possible Responses in Low and Middle-income Nations. International Institute for Environemnt and Development (ISBN: 978-1-84369-681-0 Available at: http:// www.iied.org/pubs/display.php?o=10553IIED).

MOEJ, 2014. Asian Co-benefits Partnership (ACP) White Paper 2014 Bringing Development and Climate Together in Asia. Ministry of Environment Japan (http://www. cobenefit.org/publications/images/ACPwhitepaper_FY2013.pdf).

Nagpure, A.S., Gurjar, B.R., Martel, J.C., 2014. Human health risks in national capital territory of Delhi due to air pollution. Atmos. Pollut. Res. 5 (3), 371-380.

Narain, U., Krupnick, A., 2007. The Impact of Delhi's CNG Program on Air Quality. Discussion Paper RFF DP 07-06. Resources for the Future, Washington DC.

Pierre, G., Peters, G.B., 2000. Governance, Politics and the State. St. Martins Press, New York.

Portugal-Pereira, J.C., Doll, C.N.H., Suwa, A., Puppim de Oliveira, J.A., 2013. The Sustainable Mobility-Congestion Nexus: A Co-benefits Approach to Finding Win-Win Solutions. UNESCAP Transport and Communications Bulletin for Asia and the Pacific 82 pp. 19-31. Powell, W.W., 1990. Neither market nor hierarchy. Res. Organ. Behav. 12, 295-336.

Proust, K., Newell, B., Brown, H., Capon, A., Browne, C., Burton, A., et al., 2012. Human health and climate change: leverage points for adaptation in urban environments. Int. J. Environ. Res. Public Health 9 (6), 2134-2158 2012 Jun 6.

Provan, K.G., Lemaire, R.H., 2012. Core concepts and key ideas for understanding public sector organizational networks: using research to inform scholarship and practice. Public Adm. Rev. 72 (5), 638-648.

Puppim de Oliveira, J.A., Doll, C.N.H., Kurniawan, T.A., Yong, G., Kapshe, M., 2013. Promoting win-win situations in climate change mitigation, local environmental quality and development in Asian cities through co-benefits. J. Clean. Prod. (58), 1-6 http://dx. doi.org/10.1016/j.jclepro.2013.08.011.

Puppim de Oliveira, J.A., Doll, C.N.H., Siri, J.G., Dreyfus, M., Farzaneh, H., Capon, A.G., 2015. Governance in the context of urban transformation and climate change: how urban policy based on systems approaches can lead to co-benefits for health and environment. Cad. Saude Publica 31, 25-38. http://dx.doi.org/10.1590/0102-311X00010015.

Ragin, C.C., Becker, H.S., 1992. What is a case?: exploring the foundations of social inquiry. Cambridge University Press (Jul 31).

Roychowdhury, A., 2011. Is Free Parking Our Inalienable Right? Centre for Science and Environment, Delhi, India (Available at: http://www.cseindia.org/content/free-parkingour-inalienable-right)

Roychowdhury, A., 2012. BRT Missed the Bus for the Cars. Centre for Science and Environment, Delhi, India (Available at: http://www.cseindia.org/content/brt-missed-buscars). 
Seto, K...C., Dhakal, S., Bigio, A., Blanco, H., Delgado, G.C., Dewar, D., Huang, L., Inaba, A., Kansal, A., Lwasa, S., McMahon, J.E., Müller, D.B., Murakami, J., Nagendra, H., Ramaswami, A., 2014. Human settlements, infrastructure and spatial planning. In: Edenhofer, O., Pichs-Madruga, R., Sokona, Y., Farahani, E., Kadner, S., Seyboth, K., Adler, A., Baum, I., Brunner, S., Eickemeier, P., Kriemann, B., Savolainen, J., Schlömer, S., von Stechow, C., Zwickel, T., Minx, J.C. (Eds.), Climate Change 2014: Mitigation of Climate Change. Contribution of Working Group III to the Fifth Assessment Report of the Intergovernmental Panel on Climate Change. Cambridge University Press, Cambridge, United Kingdom and New York, NY, USA.

Shah, G., 1997. Public Health and Urban Development: The Plague in Surat. Sage Publications, New Delhi.

Sharma, A., Roychowdhury, A., 1996. Slow murder: the deadly story of vehicular pollution in India. Cent. Sci. Environ. (160 pp.).
Singh, S.K., 2012. Urban Transport in India: Issues. Challenges, and the Way Forward 52 (Paper n_ 5. ISSN: 1825-3997. European Transport|Trasporti Europei).

SMC - Surat Municipal Corporation, 2016. (Webpage) www.suratmunicipal.gov.in (accessed on) (29 April).

Turrini, A., Cristofoli, D., Frosini, F., Nasi, G., 2010. Networking literature about determinants of network effectiveness. Public Adm. 88 (2), 528-559.

Uzzi, B., 1997. Social structure and competition in interim networks: the paradox of embeddedness. Adm. Sci. Q. 42 (1), 35-67.

WHO, 2014. Ambient (outdoor) air pollution in cities database 2014. (Available at:) http://www.who.int/phe/health_topics/outdoorair/databases/cities/en/. 